\title{
Production of a favorable calibration target for the determination of distortions of lenses in image processing
}

Rolf Hoffmann, Gunther Notni

Rolf Hoffmann, Gunther Notni, "Production of a favorable calibration target for the determination of distortions of lenses in image processing," Proc. SPIE 11144, Photonics and Education in Measurement Science 2019, 111441C (17 September 2019); doi: 10.1117/12.2532544

SPIE Event: Joint TC1 - TC2 International Symposium on Photonics and Education in Measurement Science 2019, 2019, Jena, Germany 


\title{
Production of a favorable calibration target for the determination of distortions of lenses in image processing
}

\author{
Rolf Hoffmann ${ }^{\mathrm{a}}$, Gunther Notni ${ }^{\mathrm{a}}$ \\ ${ }^{a}$ Technische Universität Ilmenau, Group for Quality Assurance and Industrial Image Processing, \\ Gustav Kirchhoff Platz 2, 98693 Ilmenau, GERMANY
}

\begin{abstract}
Lenses have a number of faults. The distortion is an error which has a negative effect especially in metrological applications. In extreme cases, distortion can also be visible to the naked eye. The distortion of lenses is a systematic error that can be corrected numerically. For this purpose, a target with a smaller local deviation is necessary.

These targets are produced and measured with great effort. Especially for the area of large object fields the effort increases enormously. For this reason, no correction has been made for larger measuring ranges. In order to be able to apply a correction nevertheless, a compromise solution is required that produces a target with little effort, with which a correction becomes possible that is better than not applying any correction at all. Here, calibration targets were printed and examined with commercially available printers.
\end{abstract}

Keywords: Image processing, lens, distortion, calibration target

\section{INTRODUCTION}

In order to carry out high-precision measurements with the aid of optical image processing, it is of decisive importance that the quality of the image to be measured is of particularly high quality. Low noise, contrast and other factors play a role. A major problem here are distortions in the image caused by the lens. Figure 1 shows an extreme case of distortion of a lens.

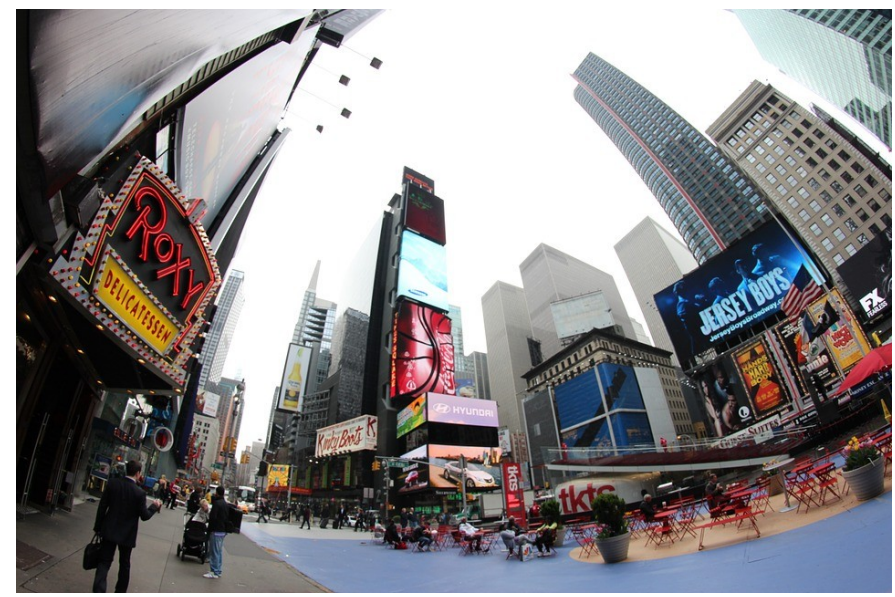

Figure 1. Fisheye effect as image distortion

In such a case, metric measurements in the image range from poor accuracy to useless measurement results. To remove the distortion, the camera system must be calibrated. This procedure requires a calibration target (Fig. 2). 


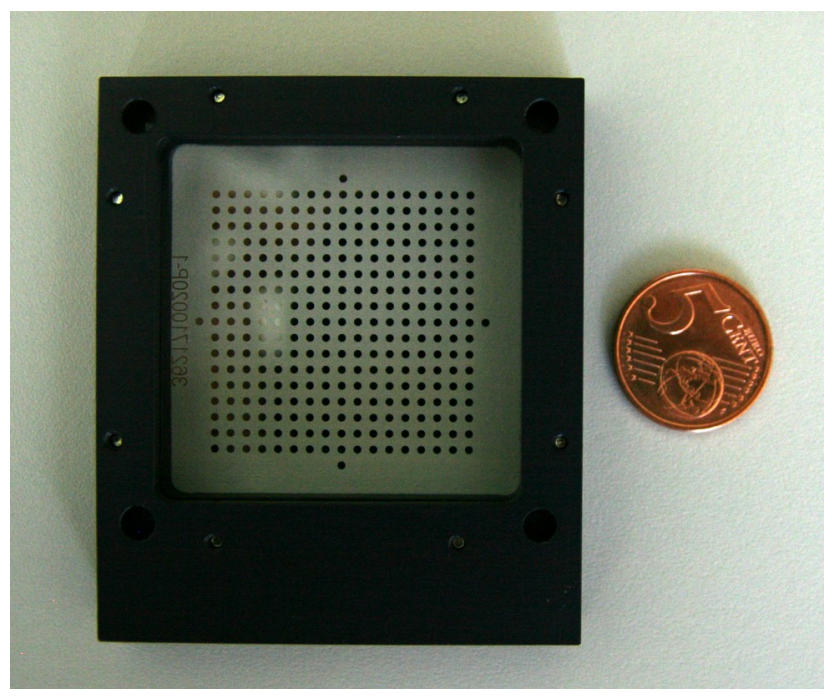

Figure 2. Chrome glass calibration target

\section{USEFUL STRUCTURES FOR CALIBRATION TARGETS}

In order to determine the exact distortion of a lens, it is necessary to determine the deviation from the actual target position for each location in the image. This requires calibration targets that fill the entire usable image area. Furthermore, the exact coordinates of all geometric elements in the calibration target must be known. Meaningful structures can be seen in the following images:

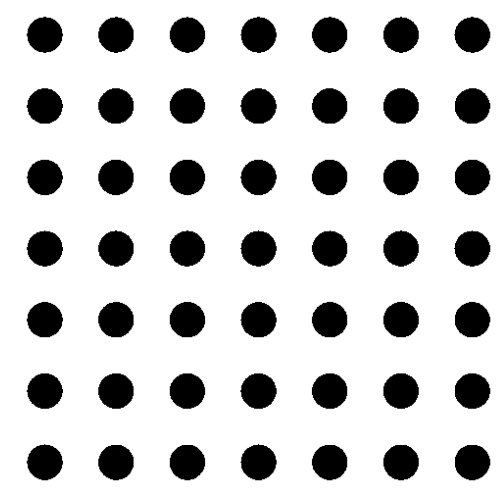

Figure 3. Point structure for a calibration target 


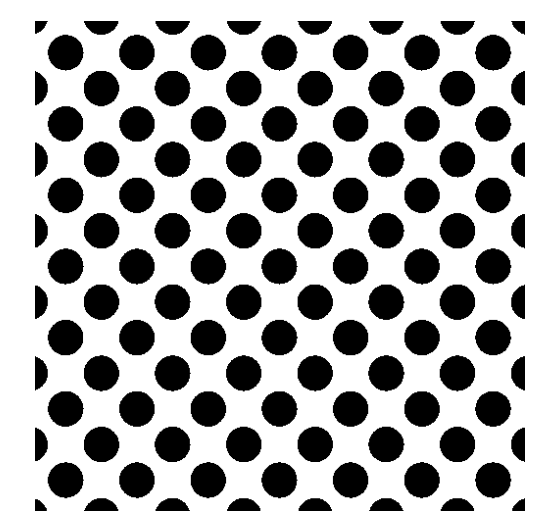

Figure 4. Alternative point structure for a calibration target

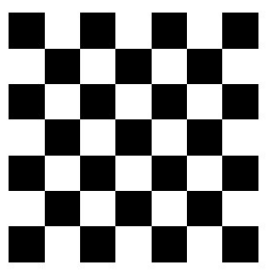

Figure 5. Checkerboard structure for a calibration target

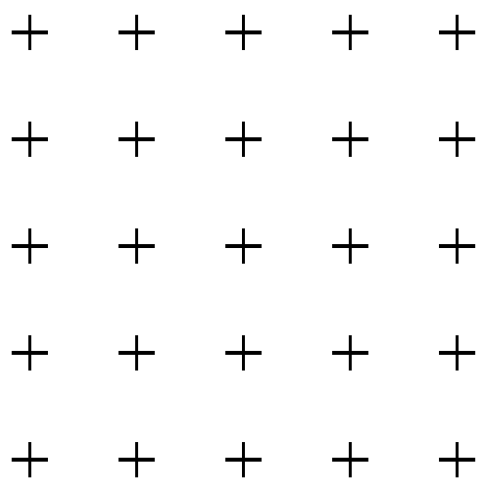

Figure 6. Crosses structure for a calibration target 


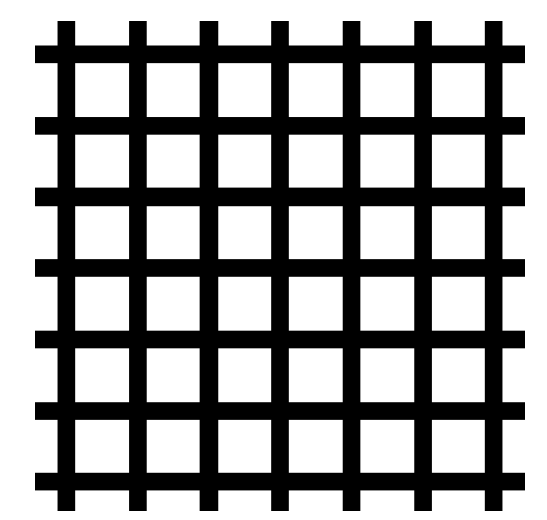

Figure 7. Grid structure for a calibration target

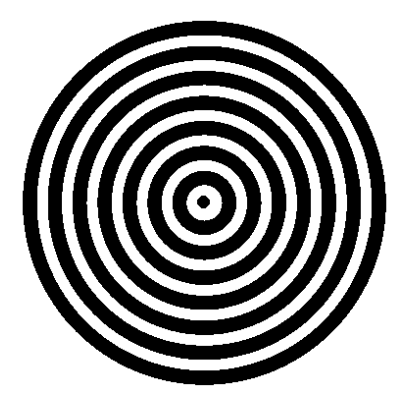

Figure 8. Rings structure for a calibration target

\section{DETERMINATION OF DISTORTION}

The positions of the geometric elements are determined in the image by means of image processing algorithms. These algorithms indicate the deviations in the image from the target positions. The determined positions serve as support points to create a flat 2D distortion correction. Figure 9 shows the image acquisition of a point structure and Figure 10 shows the probed point elements through image processing. 


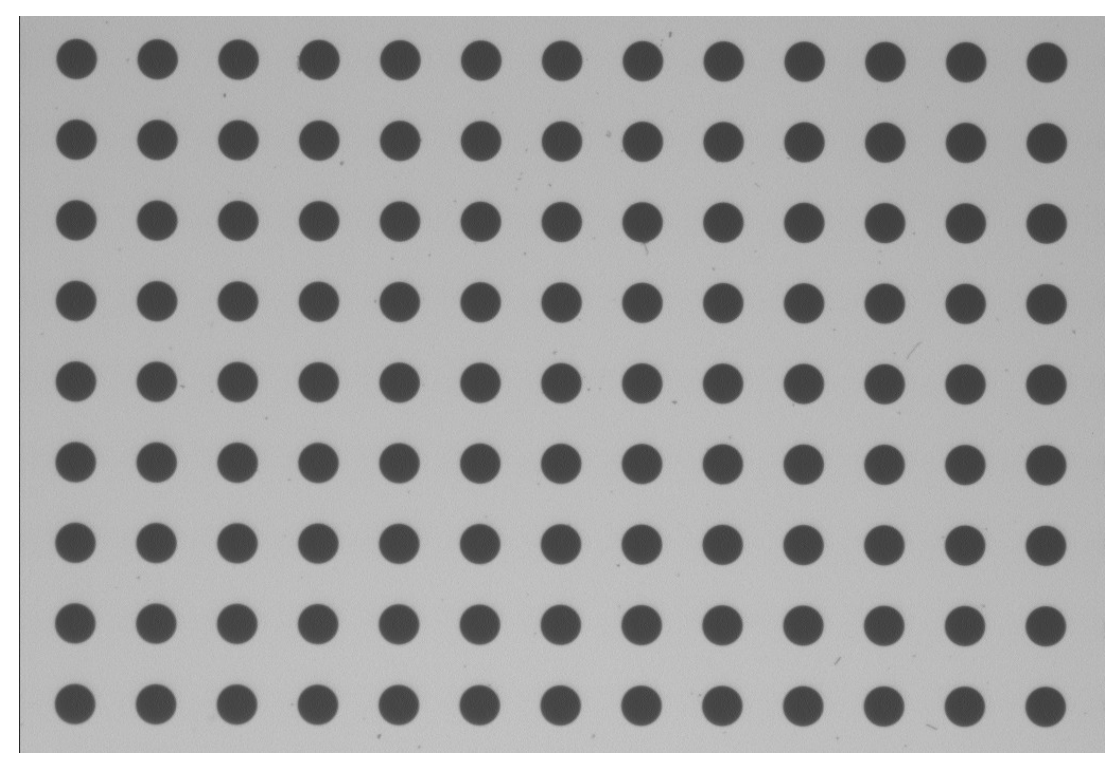

Figure 9. Image acquisition of a point structure

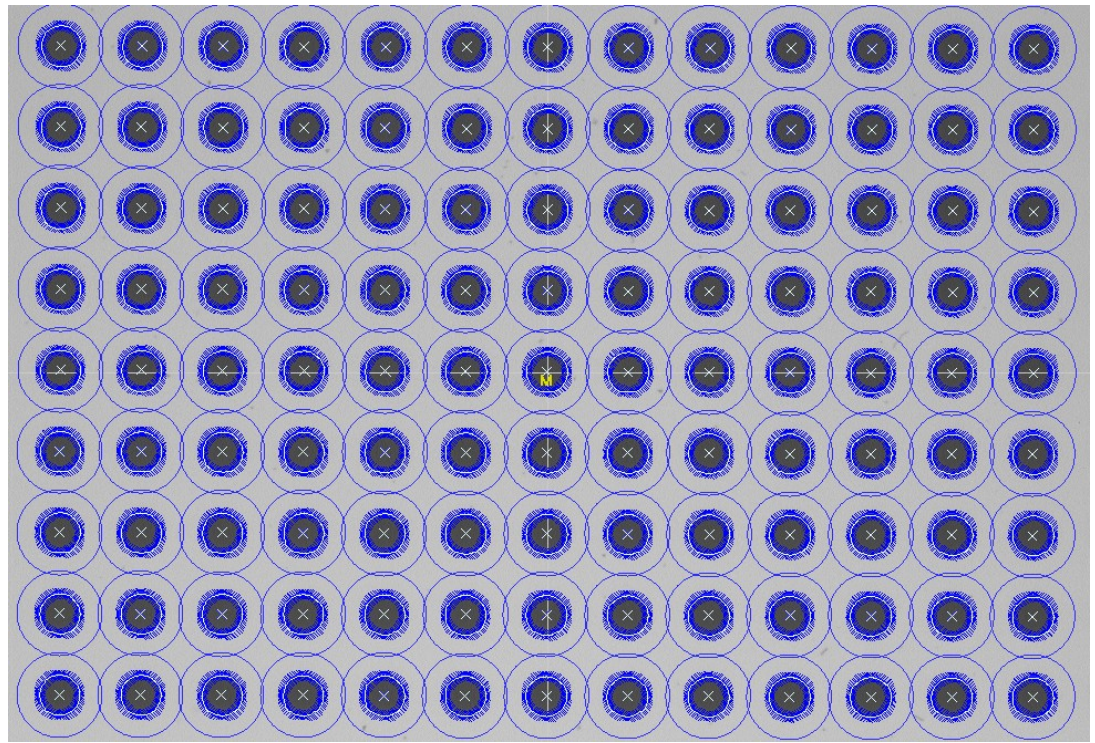

Figure 10. Detected and measured point elements

\section{QUALITY OF THE CALIBRATION TARGETS}

The exact determination of the position of the geometric elements is of essential importance. Factors influencing the accuracy of the position determination include the image parameters: Sharpness and contrast in the image, artifacts in the image and other parameters. But also the quality of the individual geometry elements on the calibration targets is of great importance and the material on which the calibration structures are applied. The following pictures show example printouts on normal copy paper, on a foil and on photo paper. Printing was done with the inkjet printer HP K7100 and the laser printer Lexmark Optra T610(MS). 


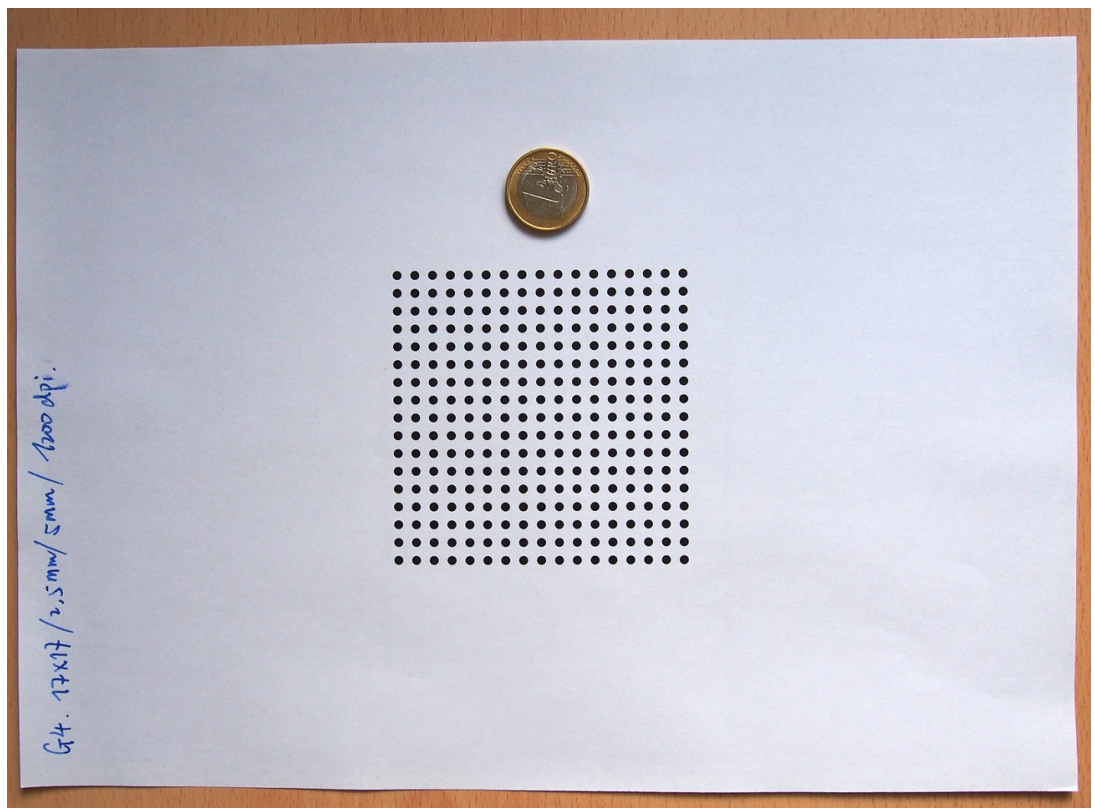

Figure 11. Normal copy paper, 1200 dpi

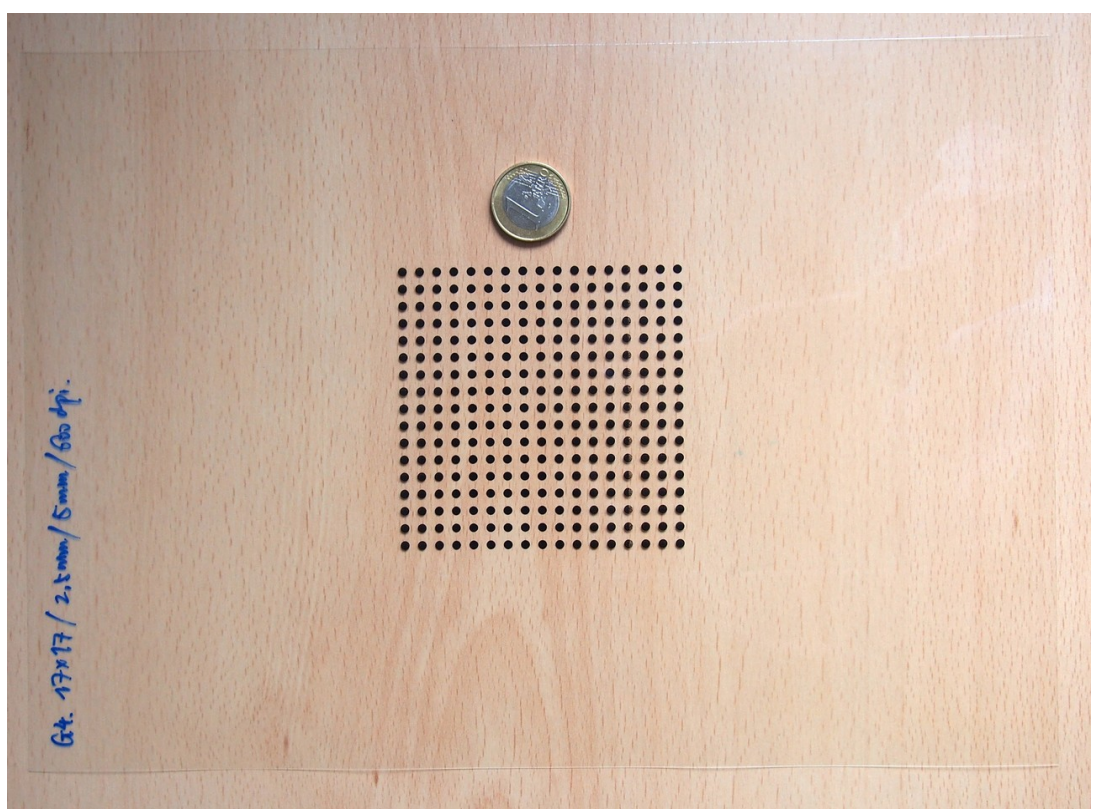

Figure 12. Foil "AVERY Zweckform Laser + Kopier-Folie", 1200 dpi

Proc. of SPIE Vol. 11144 111441C-6

Downloaded From: https://www.spiedigitallibrary.org/conference-proceedings-of-spie on 26 Apr 2023 Terms of Use: https://www.spiedigitallibrary.org/terms-of-use 


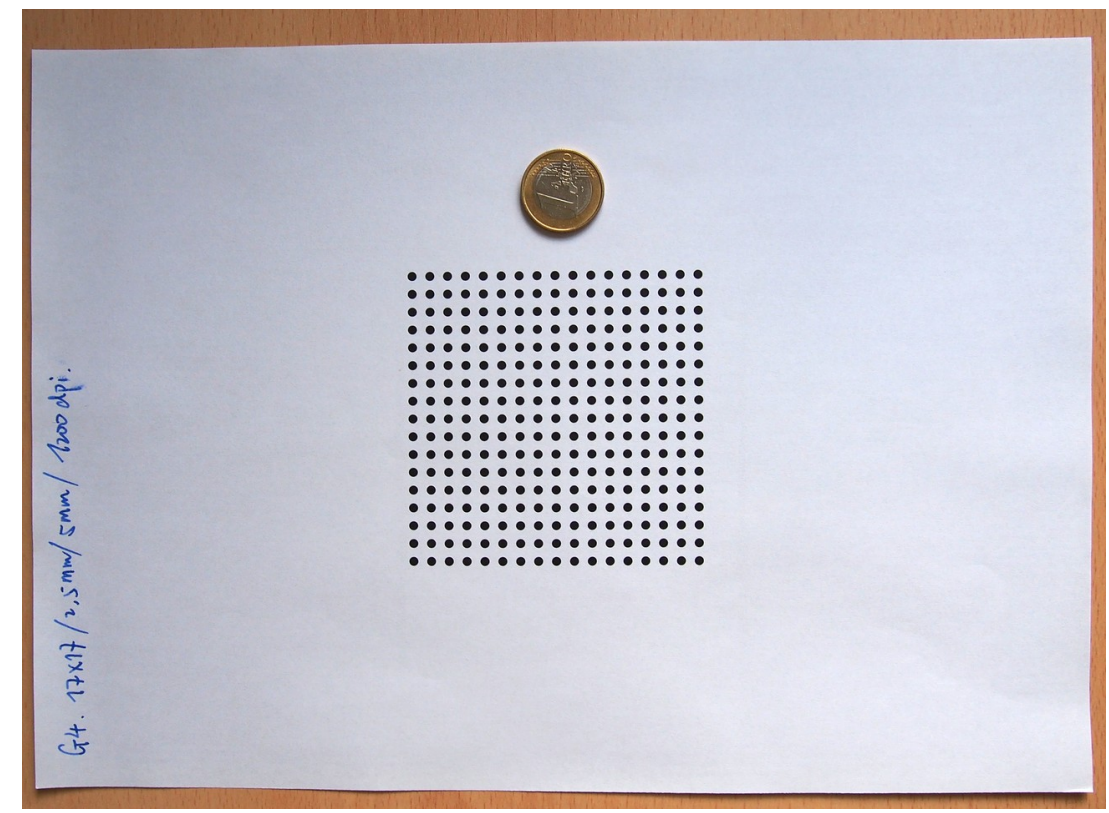

Figure 13. Photographic paper "HP Everyday Fotopapie, 600 dpi

With the UNI-VIS 250 coordinate measuring machine from Mahr OKM GmbH, the point elements of the printed calibration targets were precisely measured. This provides information on how precisely the position of the geometry elements could be printed with the printer. These values serve as reference values for quality assessment. Figures $14-16$ show an impression of the image quality of the image recordings of the calibration structures.

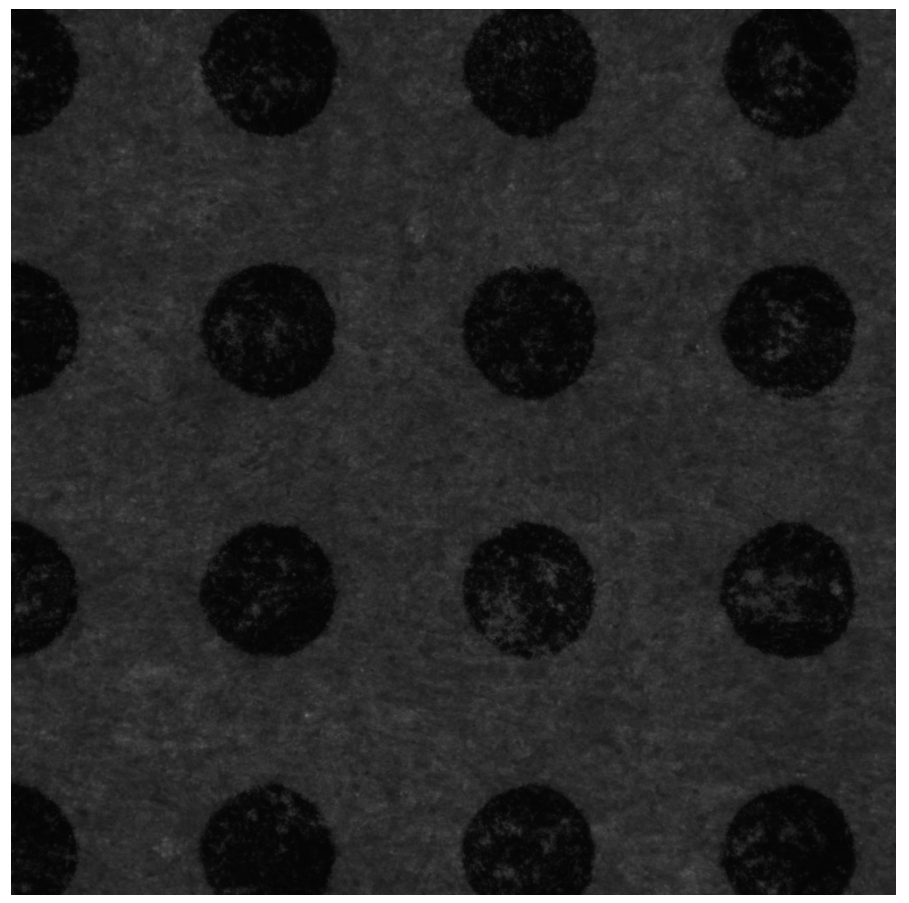

Figure 14. Normal copy paper, 1200 dpi, laser printer Lexmark Optra T610(MS), incident light 28.8\%, transmitted light $100 \%$ 


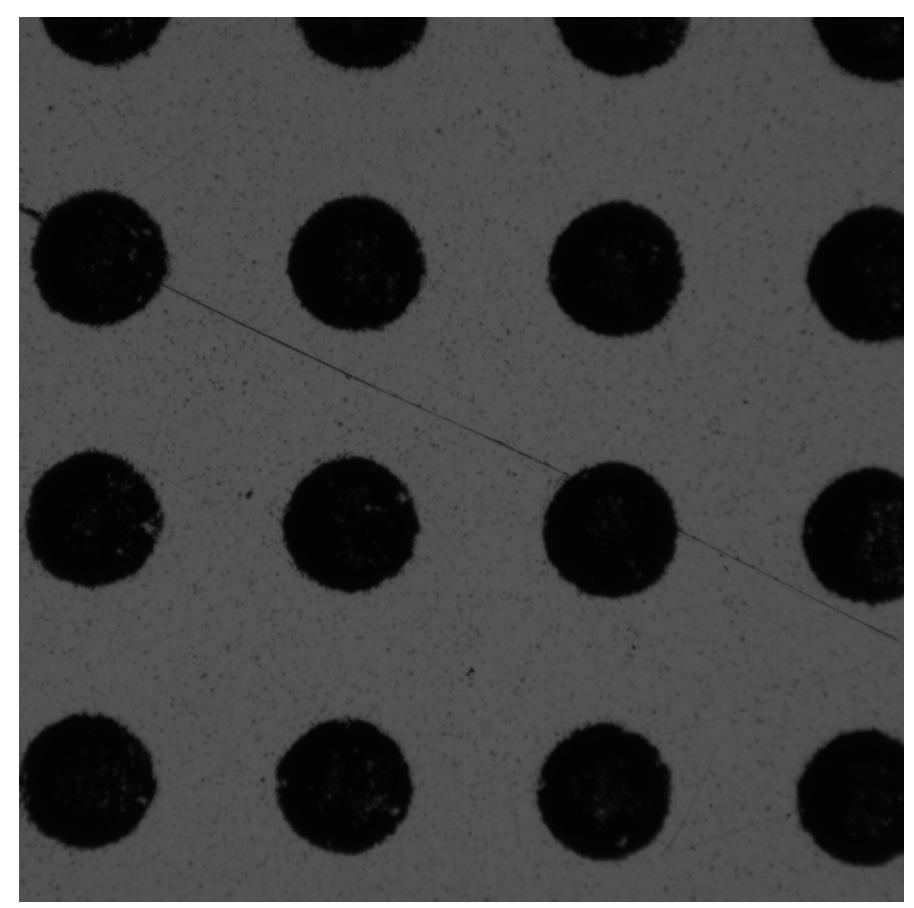

Figure 15. Foil “AVERY Zweckform Laser + Kopier-Folie”, 1200 dpi, laser printer Lexmark Optra T610(MS), incident light $0 \%$, transmitted light $16.8 \%$

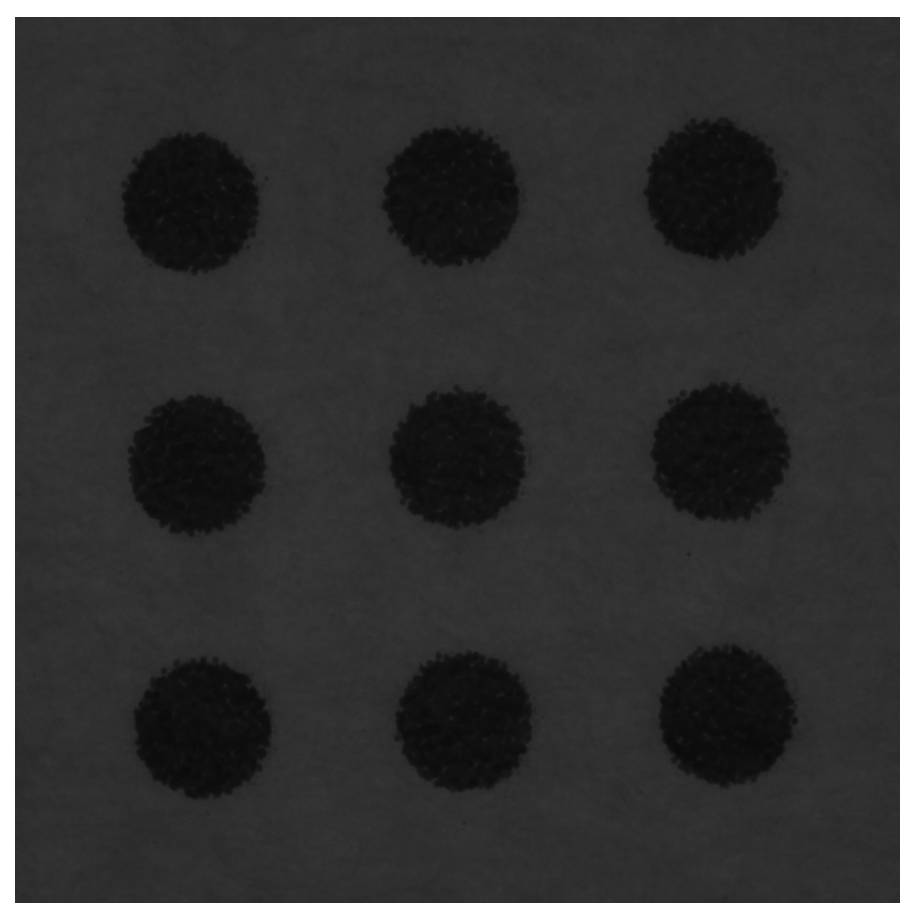

Figure 16. Photographic paper "HP Everyday Fotopapier”, 600 dpi, laser printer Lexmark Optra T610(MS), incident light $40 \%$, transmitted light $100 \%$ 
Since the material printed on (paper, foil), is not ideal to achieve the highest image quality, there are losses in the achievable measurement accuracy.

Depending on the selected print resolution and the resolution of the optical system, dots of the printing process are more or less recognizable (Fig. 17).

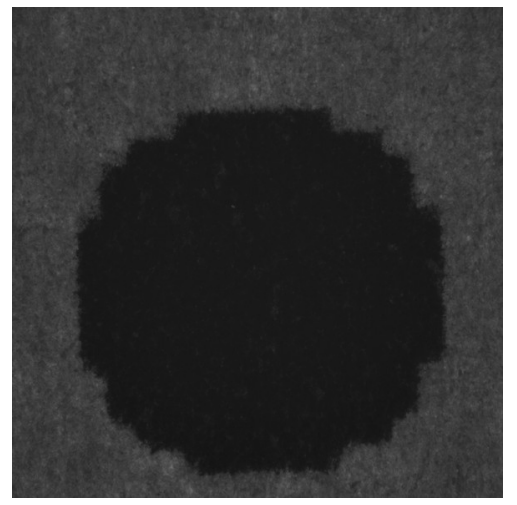

Figure 17. Visible dots of the printing process, normal copy paper, 72 dpi, inkjet printer HP K7100, incident light 52\%, transmitted light $100 \%$

In comparison, a professionally manufactured calibration standard looks like Figure 18.

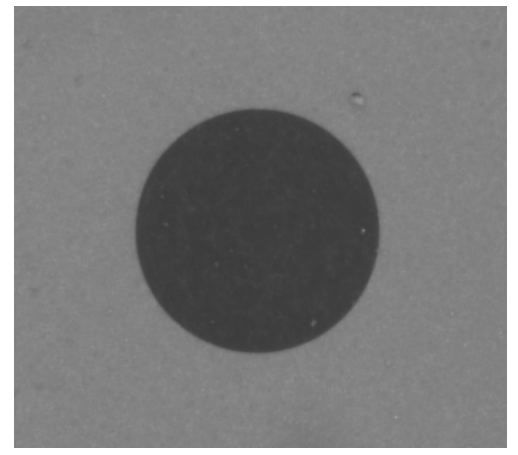

Figure 18. A cutout of the "Sample of optical calibration plate" of IMT Masken und Teilungen AG, incident light 99.6\%, transmitted light $76.8 \%$

The position deviations of the point elements, measured with the UNI-VIS 250 coordinate measuring machine from Mahr OKM GmbH, can be seen in image diagrams $19-23$. 


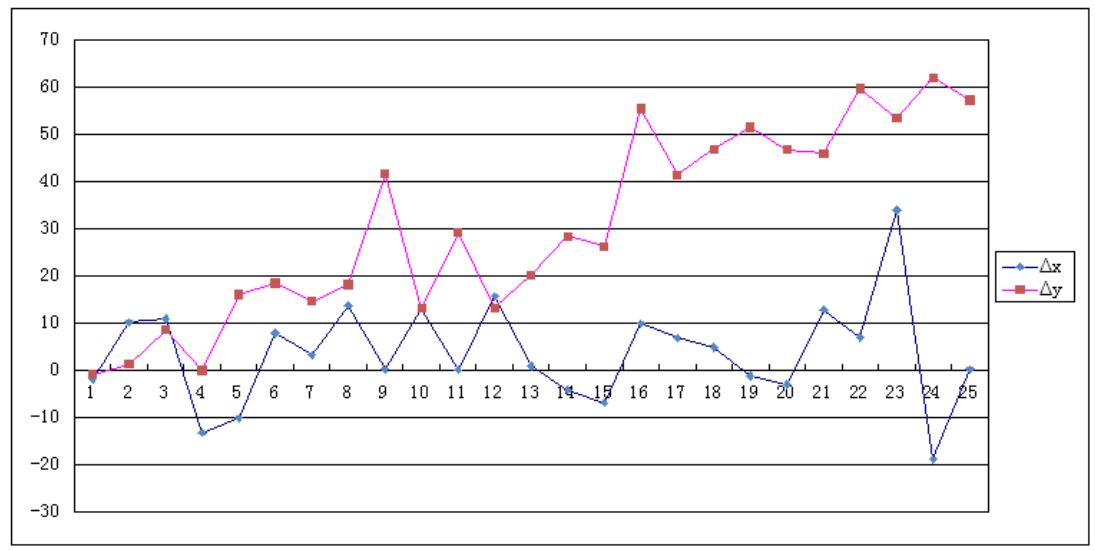

Figure 19. Position deviations [ $\mu \mathrm{m}]$, normal copy paper, 1200 dpi, laser printer Lexmark Optra T610(MS)

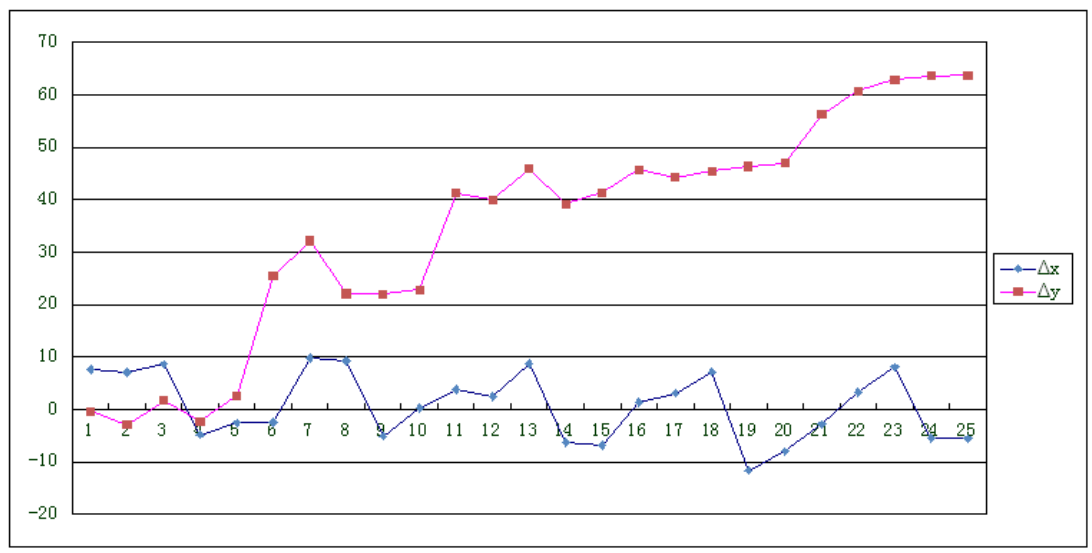

Figure 20. Position deviations [ $\mu \mathrm{m}$ ], foil “AVERY Zweckform Laser + Kopier-Folie”, 1200 dpi, laser printer Lexmark Optra T610(MS)

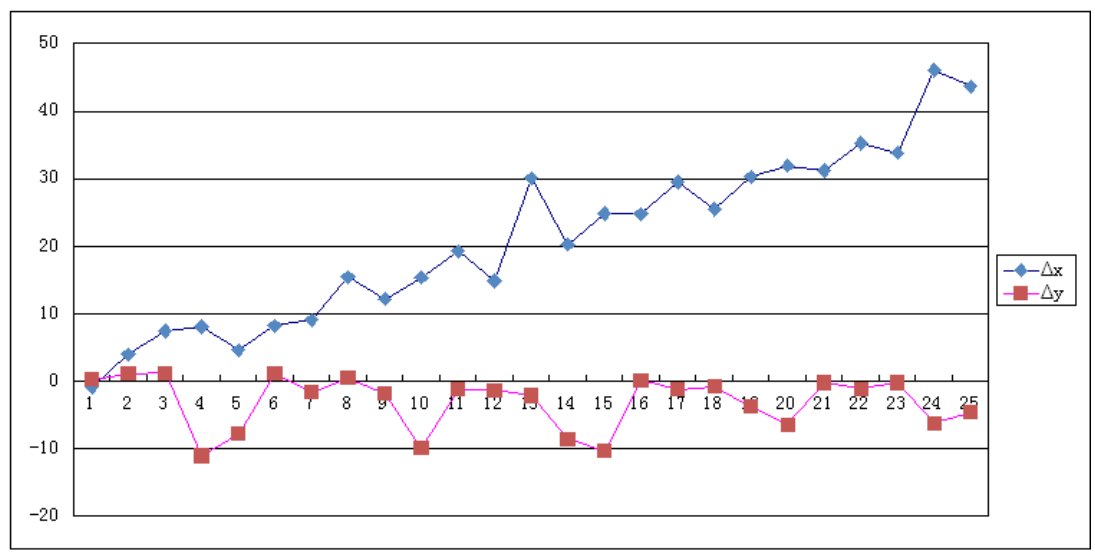

Figure 21. Position deviations [ $\mu \mathrm{m}]$, photographic paper "HP Everyday Fotopapier", 600 dpi, laser printer Lexmark Optra T610(MS) 


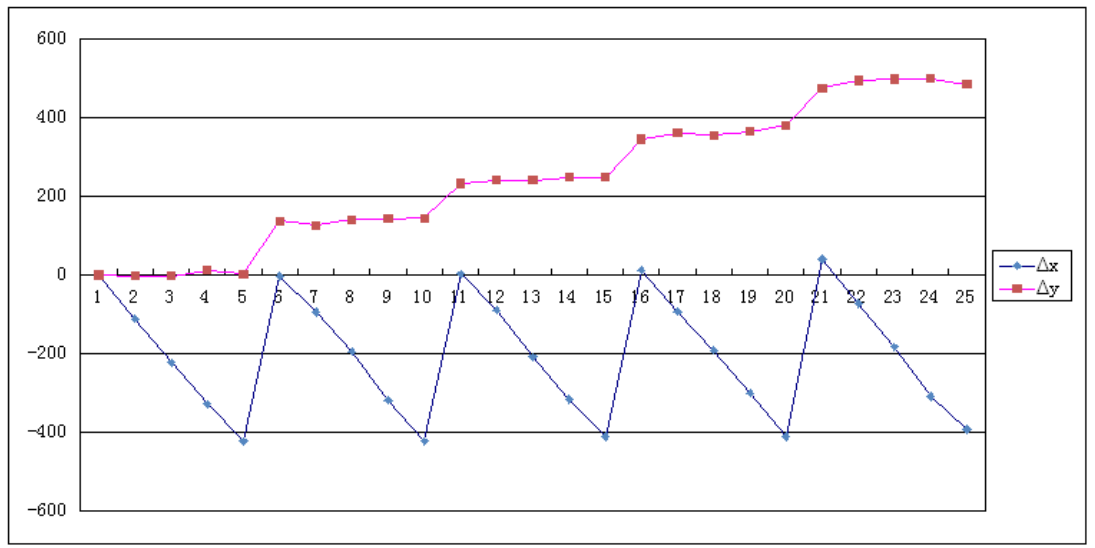

Figure 22. Position deviations $[\mu \mathrm{m}]$, normal copy paper, 72 dpi, inkjet printer HP K7100

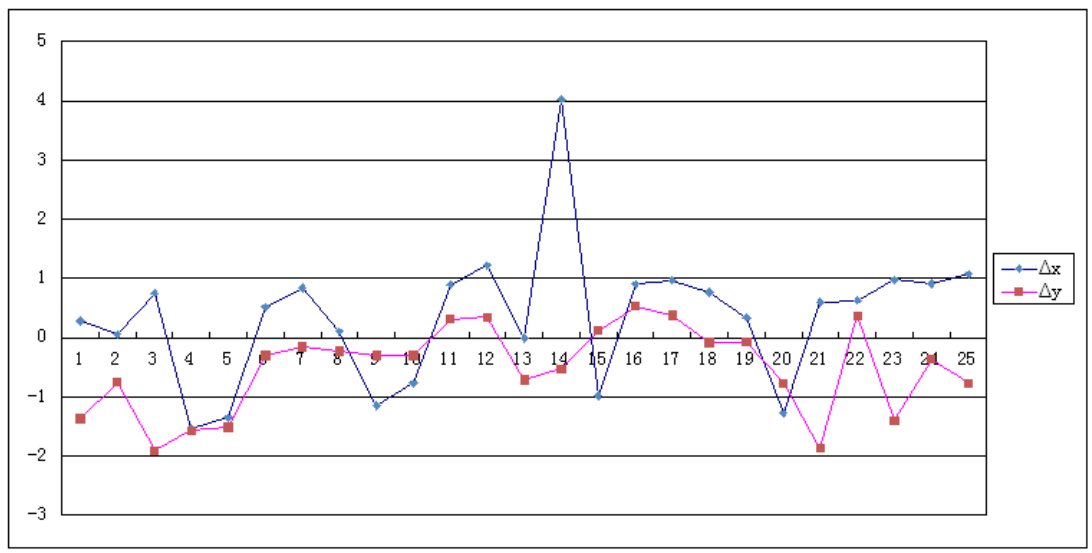

Figure 23. Position deviations $[\mu \mathrm{m}]$, "Sample of optical calibration plate" of IMT Masken und Teilungen AG

\section{CONCLUSIONS}

It is possible to produce calibration targets with commercially available equipment (printers, print media). Depending on the printing technology and printing medium, the position deviations of the geometric elements can be an order of magnitude worse than those of a professionally produced calibration standard. Depending on the printer, periodic deviation errors can occur, which exist as systematic errors in addition to random errors.

Thus, this represents a cost-effective and practicable solution for the simple production and use of calibration targets.

\section{REFERENCES}

[1] Steger, Carsten, Ulrich, Markus, Wiedemann, Christian, "Machine Vision Algorithms and Applications," Weinheim, Wiley-VCH Verlag GmbH \& Co. KgaA (2007).

[2] Jähne, Bernd, "Digitale Bildverarbeitung und Bildgewinnung," 7. Auflage, SpringerVerlag, Berlin (2012). 
[3] Zhang, Z, "A flexible new technique for camera calibration. IEEE Trans. On Pattern Analysis an Machine Intelligence (PAMI)," 22(11), 1330-1334 (2000).

[4] Tu, Huanbo, "Entwurf und Herstellung eines Normals zur Aufnahme der Verzeichnungen von Objektiven im Makrobereich," Bachelor thesis, Technische Universität Ilmenau (2014).

[5] Steinbrecher, Rainer, "Bildverarbeitung in der Praxis," Oldenbourg Verlag, München (1993). 